\title{
Prediction of Key Candidate Genes for Platinum Resistance in Ovarian Cancer
}

\author{
Kaidi Guo iD ${ }^{1,2, *}$ \\ Li Li (iD ${ }^{1,2, *}$ \\ 'Department of Gynecology and \\ Oncology, Guangxi Medical University \\ Cancer Hospital, Nanning, Guangxi, \\ People's Republic of China; ${ }^{2}$ Key \\ Laboratory of Early Prevention and \\ Treatment for Regional High Frequency \\ Tumor, Ministry of Education, Nanning, \\ Guangxi, People's Republic of China \\ *These authors contributed equally to \\ this work
}

\begin{abstract}
Purpose: Ovarian cancer is one of the common malignant tumors of female reproductive organs, which seriously threatens the life and health of women. Resistance to chemotherapeutic drugs for ovarian cancer is the root cause of recurrence in most patients. The purpose of this study is to determine the differentially expressed genes of platinum resistance in ovarian cancer, and to screen out molecular targets and diagnostic markers that could be used to treat ovarian cancer platinum resistance.
\end{abstract}

Methods: We downloaded 5 gene microarray datasets GSE58470, GSE45553, GSE41499, GSE33482, and GSE15372 from the Gene Expression Omnibus database, all of which are associated with ovarian cancer platinum resistance. Subsequently, the intersection of the statistically significant differentially expressed genes in 5 gene chips was taken, and relevant bioinformatics and clinical parameters were performed on the screened differential genes. qRT-PCR was utilized to examine the mRNA expression levels in ovarian cancer sensitive and cisplatin-resistant cells.

Results: Three differential genes, IFI27, JAG1, DNM3, may be closely related to platinum resistance of ovarian cancer, were screened by microarray datasets. According to the combined verification of bioinformatics, clinical case analyses and experiments, it was inferred that the increased expression of $D N M 3$ was beneficial to patients with platinum resistance, but the high expression of IFI27 and JAG1 may lead to the risk of platinum resistance.

Conclusion: IFI27, JAG1 and DNM3 screened by relevant gene chips may serve as new biomarkers of platinum resistance in ovarian cancer.

Keywords: ovarian cancer, platinum resistance, bioinformatical analysis, differentially expressed genes

\section{Introduction}

Ovarian cancer is one of the common malignancies of female reproductive organs, which seriously threatens the life and health of women. Because the ovaries are deep in the pelvic cavity, small in size, lack of typical symptoms, and effective screening methods, it is difficult to detect early. About $75 \%$ of patients with ovarian cancer have been diagnosed as advanced stage, with peritoneal spread or distant metastasis. ${ }^{1,2}$ Tumor cytoreductive surgery combined with postoperative adjuvant chemotherapy is a common clinical treatment for patients with advanced ovarian cancer. Chemotherapy drugs for ovarian cancer mainly include periodic non-specific platinum and cyclespecific paclitaxel. Platinum hinders DNA synthesis and mitosis in cancer cells by cross-linking with DNA, while paclitaxel can strengthen tubulin polymerization and inhibit tubulin depolymerization. ${ }^{3}$ However, even if the initial chemotherapy treatment effect is good, most patients are prone to multidrug resistance, that is, as long as the
Correspondence: Li Li

Department of Gynecology and

Oncology, Guangxi Medical University

Cancer Hospital, Nanning, Guangxi,

530021 , People's Republic of China

Tel +86 I38 78I I 3406

Email lili@gxmu.edu.cn 
resistance to one of the chemotherapeutic drugs, they will be resistant to other chemotherapy drugs with different structures and mechanisms. As the most commonly used chemotherapeutic drug in clinical practice, platinum is quite frequently resistant in the treatment of ovarian cancer. At present, the widely used detection indicators for ovarian cancer lack specificity and sensitivity. Therefore, it is urgent to discover the marker genes related to platinum resistance in ovarian cancer.

\section{Materials and Methods \\ Source of Information GEO Microarray System Retrieval Strategy}

Keywords: "ovarian carcinoma” OR "ovarian cancer" OR "chemotherapy resistance" OR "platinum resistance"; restricted species was "Homo sapiens", to search for gene expression profiles related to platinum resistance in ovarian cancer that had been publicly reported in the GEO before 2021. Finally, 21 datasets were retrieved.

\section{Inclusion Criteria}

(1) The dataset must be a comparative study on platinumsensitivity and resistance of ovarian cancer; (2) The downloaded data is the original dataset or standardized processing; (3) Each group of control (sensitive) and case (resistant) in the dataset must include or exceed 3 samples; (4) Clear information on the sensitivity and resistance of each sample to platinum must be given. Datasets that meet the above criteria will be included in this study. In the end, there are 5 datasets that meet our inclusion criteria, namely GSE58470, GSE45553, GSE41499, GSE33482, and GSE15372. Among them, GSE58470 contains sensitive cells IGROV-1 and oxaliplatin-resistant cells IGROV-1/OHP; GSE45553 is obtained from cisplatin-sensitive and resistant human ovarian cancer spheroids; GSE41499 is a dataset on platinumsensitive PEO1 and platinum-resistant PEO4 cells; the genetic data for GSE33482 is derived from A2780 cisplatinsensitive and A2780cis-resistant cells; and GSE15372 is based on the dataset of A2780 and cisplatin-resistant Round5 A2780 cells.

\section{Methods}

\section{GEO2R for Expression Analysis}

GEO2R, the official tool of GEO database, was used to analyze the differential expression levels of target genes in ovarian cancer platinum-resistant gene chips to observe the expression contents in ovarian cancer cells. GraphPad Prism 8 was performed for data visualization in this study.

\section{To Verify the Expression of Target Genes in Ovarian Cancer Cells \\ CCK-8 Detection of Cell Resistance Index (RI)}

The ovarian cancer sensitive cells A2780 and SKOV3 and the cisplatin-resistant cells A2780-DDP and SKOV3-DDP used in this work were purchased, sequenced and identified through regular channels from Shanghai Yiyan Biotechnology Co., Ltd (China). The cell density inoculated on the 96 -well cell culture plate was $5 \times 10^{\wedge} 3$ cells/ well. Six cisplatin concentration gradients were established in each group, which were $0,0.39 \mu \mathrm{g} / \mathrm{mL}, 0.78$ $\mu \mathrm{g} / \mathrm{mL}, 1.56 \mu \mathrm{g} / \mathrm{mL}, 3.125 \mu \mathrm{g} / \mathrm{mL}, 6.25 \mu \mathrm{g} / \mathrm{mL}$, with 5 replicate holes for each concentration. After culturing for 48 hours, $100 \mu \mathrm{L}$ of complete medium containing $8 \%$ CCK-8 was added to each well, and the optical density (OD) at $450 \mathrm{~nm}$ was detected after 1.5 hours. The inhibitory rate is calculated according to Equation 1. The experimental wells contained cisplatin drugs, while the control group did not, and the blank wells had no cells. The $\mathrm{IC}_{50}$ value was obtained by statistical software to calculate the drug concentration required when $50 \%$ of cells were suppressed, and the RI is computed according to Equation 2.

$$
\begin{aligned}
\text { Cell inhibition rate }= & 1-\frac{\text { OD Experimental }- \text { OD Blank }}{\text { OD Control }- \text { OD Blank }} \\
& \times 100 \%
\end{aligned}
$$

$$
\mathrm{RI}=\frac{\text { Drug }- \text { resistant cell IC50 }}{\text { Sensitive cell IC50 }}
$$

To Test the mRNA Expression Levels of Target Genes in Sensitive and Drug-Resistant Ovarian Cancer Cells by Q-PCR

The Trizol Reagent used to extract cellular RNA was purchased from Invitrogen (USA). The RevertAid FirstStrand cDNA Synthesis Kit applied in the reverse transcription was bought from Thermo Scientific (USA). The primer sequences of IFI27, JAG1, DNM3 and internal reference $G A P D H$ are shown in Table 1, which were synthesized by Shanghai Sangon Biotech. And the SYBR Advantage qPCR Premix kit achieved for qRT-PCR was gained from TAKARA (Japan).

All operating supplies were processed by RNase-free. The experimental results of Q-PCR were expressed as CT values. $\Delta \mathrm{CT}$ is calculated from Equation 3, and $\Delta \Delta \mathrm{CT}$ is computed according to Equation 4. The mRNA expression in control group was set to 1 , and the reckoned relative quantification was $2^{\wedge}-\Delta \Delta \mathrm{CT}$, which represented the 
Table I Primer List for Q-PCR

\begin{tabular}{|l|l|}
\hline Primer Name & Primer Sequences (5' '-3') $^{\prime}$ \\
\hline IFI27 Forward Primer & TGCTCTCACCTCATCAGCAGT \\
IFI27 Reverse Primer & CACAACTCCTCCAATCACAACT \\
JAGI Forward Primer & GTCCATGCAGAACGTGAACG \\
JAGI Reverse Primer & GCGGGACTGATACTCCTTGA \\
DNM3 Forward Primer & TCGAGGGTCGGGCATTGTA \\
DNM3 Reverse Primer & CTTCAATCTCAAGGCGAACTTCA \\
GAPDH Forward Primer & GGATCTCGCTCCTGGAAGATG \\
GAPDH Reverse Primer & GGGAACACAAAAGACCTCTTCT \\
\hline
\end{tabular}

expression multiple of experimental group relative to the control group.

$$
\Delta \mathrm{CT}=\mathrm{CT} \text { Target }-\mathrm{CT} \text { GAPDH }
$$

$\Delta \Delta \mathrm{CT}=\Delta \mathrm{CT}$ Experimental group $-\Delta \mathrm{CT}$ Control group

\section{TCGA Public Database for Clinical Case Analysis}

The gene expression and clinical follow-up information of ovarian cancer clinical samples were downloaded from the official application tool GDC apps provided by TCGA database in this part, and organized the information into a matrix through R software, and conducted clinicopathological parameters in combination with public databases. A total of 362 clinical samples were included, excluding 108 patients without chemotherapy outcomes, and 254 patients who received standard chemotherapy in combination with platinum-based agents, including carboplatin, cisplatin, and oxaliplatin. According to the 2020 National Comprehensive Cancer Network (NCCN) guidelines, after the initial cytoreductive surgery and receiving more than 3 courses of regular chemotherapy, the recurrence is confirmed in a relatively short period of time, it is generally considered that the relapse within 6 months after the completion of chemotherapy is regarded as chemoresistance. Chemosensitivity is defined as patients who have received more than 3 courses of regular chemotherapy after the initial cytoreductive surgery and have achieved clinical remission, and have recurred more than 6 months after stopping chemotherapy. Therefore, there were 205 cases in the platinum-sensitive group and 49 cases in the resistant group. Based on the average of target gene expression levels, ovarian cancer specimens in TCGA were divided into low-expression and high-expression to analyze the relationship between IFI27, $J A G 1, D N M 3$ and platinum resistance. SPSS was performed for data analysis, and $\chi^{2}$ test was used for clinicopathological parameters.
To Research the Relationship Between Gene Expression and the Clinical Prognosis of Ovarian Cancer

Survival Analysis of Sensitive and Resistant Tissues Clinical follow-up information was downloaded from TCGA and arranged into a matrix. The samples of platinum-sensitive and resistant cases were grouped by the description in the previous item. Overall survival (OS) is defined as the time from diagnosis to death due to ovarian cancer. Progression-free survival (PFS) is defined as the time from the patient's initial treatment to tumor progression. Survival analysis was performed using KaplanMeier survival curve and Log rank test for comparison.

Binary Logistic Assessment of Risk Factors Affecting Platinum-Resistant Patients

Since the dependent variable "degree of resistance" was a binary variable, the binary logistic regression was used to identify the risk factors influencing patients with platinum resistance in ovarian cancer. Other covariates were grouped according to the description of clinical parameter, all of which were categorical covariates.

To Evaluate the Diagnostic Value of Genes as Indicators of Ovarian Cancer Sensitivity

TCGA clinical cases were divided into platinum-sensitive and resistant group, and the accuracy of IFI27, JAGI and $D N M 3$ as diagnostic indicators was evaluated by ROC curve and corresponding data.

\section{Results}

\section{Screening of Differential Genes for Platinum Resistance in Ovarian Cancer}

The genes with significant differences in 5 gene chips were filtered according to the rules of P. Value $<0.01, \log \mathrm{FC}<-1$ or $\log \mathrm{FC}>1$. GSE58470 had 678 significantly differential genes, of which 445 genes were down-regulated and 233 genes were up-regulated. There were 3191 evidently differential genes in GSE45553, 1561 genes were down-regulated and 1630 genes were up-regulated. There were 1426 differentially expressed genes in GSE41499, of which 706 genes were down-regulated and 720 genes were up-regulated. GSE33482 had 3334 notably differential genes, of which 1404 genes were down-regulated and 1930 genes were up-regulated. There were 2290 differentially expressed genes in GSE15372, and 1657 genes were down-regulated and 633 genes were upregulated. The significantly different genes in 5 gene chips were input into the Venn list box and the intersection was taken 
to screen out 3 common differential genes: IFI27, JAGI and $D N M 3$. The Venn diagram is shown in Figure 1.

\section{Analysis Results of Differential Genes by GEO2R}

GEO2R analysis tool was utilized to identify the expression levels of $I F I 27, J A G 1$, and DNM3 in 5 gene microarray datasets. Through calculation and comparison, it was found that the expression levels of IFI27 and JAG1 were higher in resistant ovarian cancer cells than that in sensitivity. Compared to the resistance, DNM3 expression was greater in the platinum-sensitive group. Figure 2 shows the statistical atlas after data visualization analysis.

\section{To Verify Gene Expression in Ovarian Cancer Cells \\ CCK-8 Detects Cell Resistance Index (RI)}

The results displayed that the resistance indices of A2780DDP and SKOV3-DDP cells were 2.53 and 3.60, respectively, and the differences were statistically significant, as shown in Figure 3.

\section{To Test the Gene mRNA Expression by Q-PCR}

Since the results obtained by GEO2R were not completely consistent, PCR was used to further examine the levels of 3 genes in different ovarian cancer cells. According to quantitative calculations, IFI27 and JAG1 were highly expressed in A2780-DDP and SKOV3-DDP cisplatinresistant cells; while DNM3 expression was significantly reduced in resistance. See Figure 4 for details.

\section{TCGA Dataset Analysis Results}

The Relationship Between Gene Expression and Clinicopathological Parameters in Patients with Ovarian Cancer

Two hundred and fifty-four clinical samples were collected after removing unavailable data, including 205 cases in the platinum-sensitive group and 49 cases in resistant group. The expression of differential genes in platinum sensitive

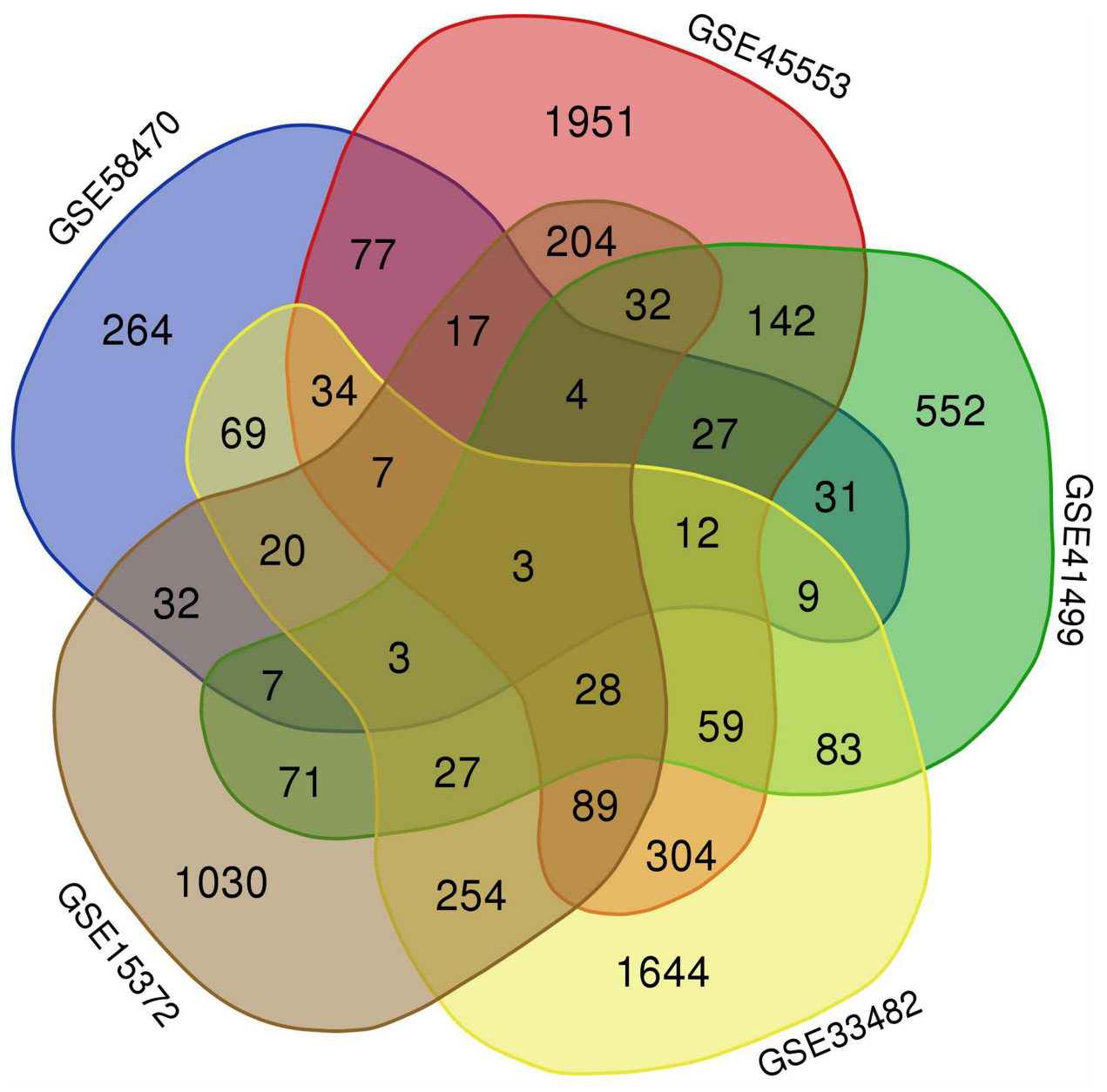

Figure I Venn diagram. 
A
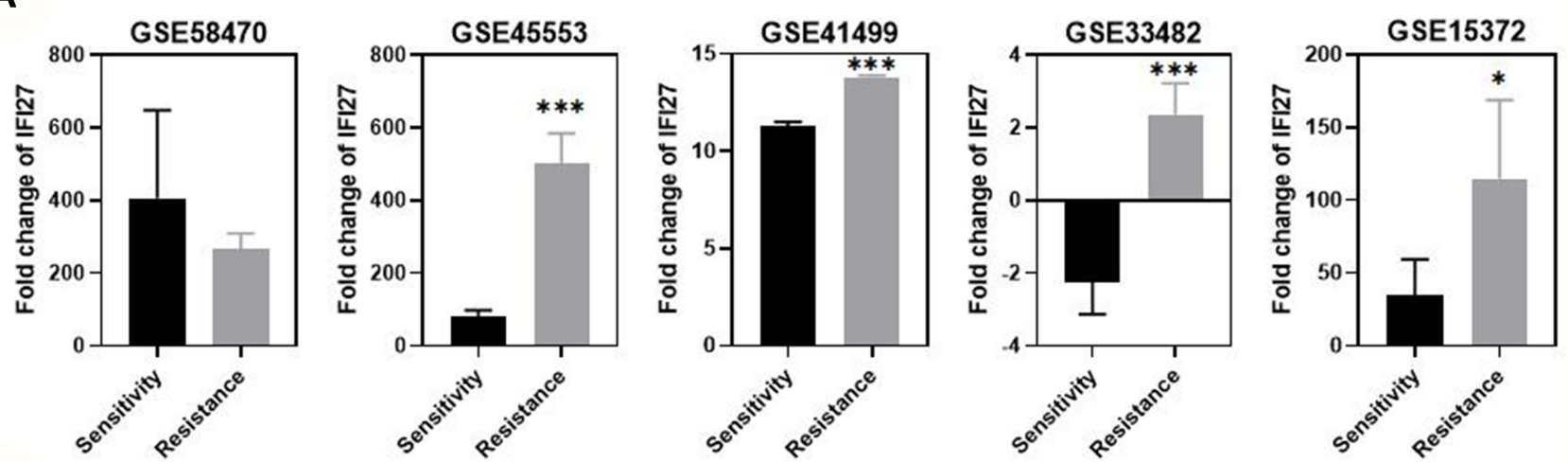

B
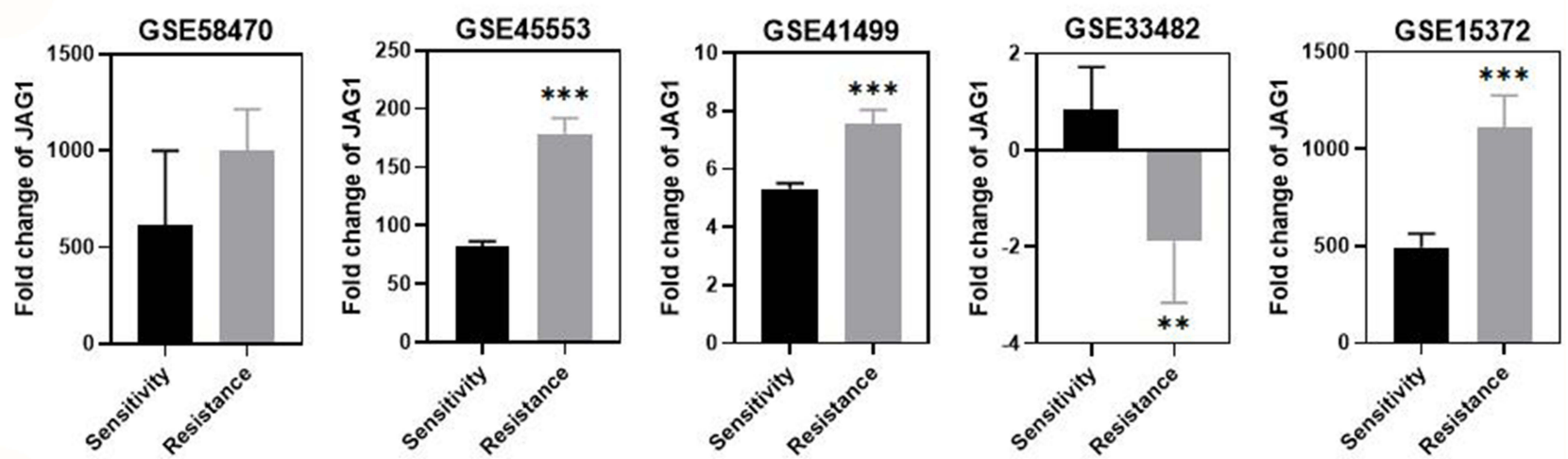

C
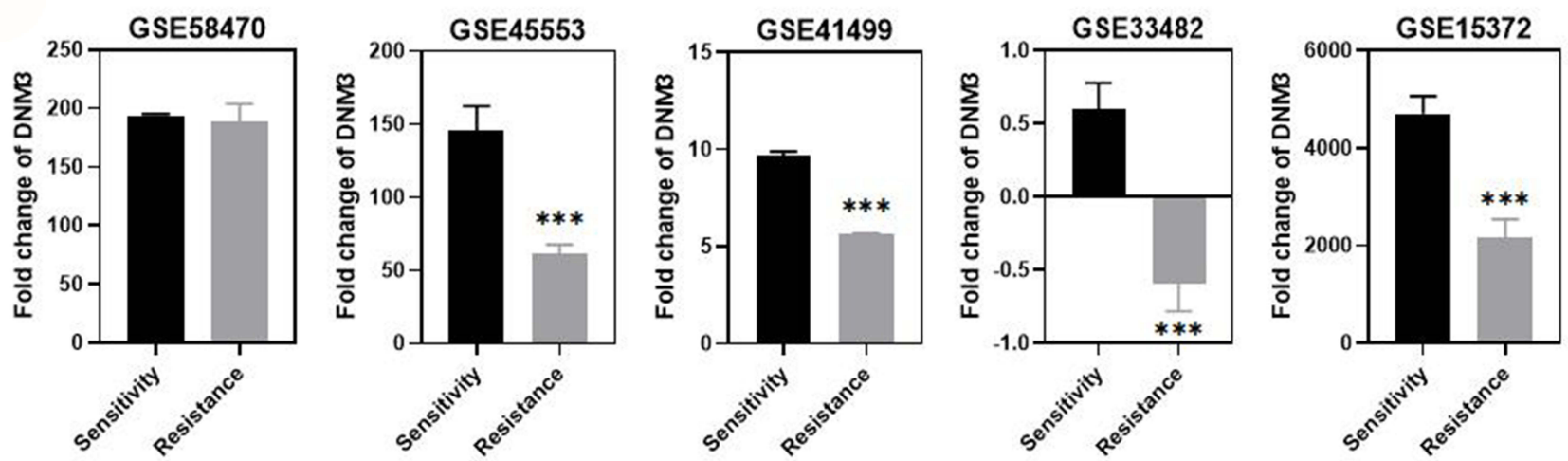

Figure 2 Statistical Analysis of 3 genes in ovarian cancer sensitive and drug-resistant cells from 5 gene chips. (A) The expression level of IFI27 in 5 gene chips; (B) The expression level of JAGI; (C) The expression level of DNM3.

Notes: $* \mathrm{P}<0.05, * * \mathrm{P}<0.01, * * * \mathrm{P}<0.005$.

and resistant patients with ovarian cancer was analyzed. The expression levels of IFI27 and JAGI in platinumresistant patients were higher, it was regrettable that the corrected IFI27 group did not have statistical difference, while DNM3 in sensitive patients was significantly greater than that in resistant cases $(\mathrm{P}<0.01)$. The graph made by GraphPad Prism is shown in Figure 5.

The expression of IFI27 was correlated with resistance of patients $\left(\chi^{2}=8.352, \mathrm{P}<0.005\right)$, tumor residue $\left(\chi^{2}=11.401\right.$, $\mathrm{P}<0.005)$ and survival status $\left(\chi^{2}=4.706, \mathrm{P}<0.05\right)$, but it may not be related to the other 4 clinicopathological parameters. There was a connection between $J A G 1$ expression and platinum-resistance $\left(\chi^{2}=5.617, \mathrm{P}<0.05\right)$ or recurrence $\left(\chi^{2}=6.314, \mathrm{P}<0.05\right)$, but it may not be connected to the other 5 parameters. DNM3 was associated with resistance of clinical cases $\left(\chi^{2}=4.278, \mathrm{P}<0.05\right)$, recurrence $\left(\chi^{2}=5.632, \mathrm{P}<\right.$ $0.05)$ and FIGO stage $\left(\chi^{2}=8.175, \mathrm{P}<0.005\right)$, but there may be no correlation with age, histological grade, tumor residue and survival status. The analysis results of the clinicopathological parameters in each gene are shown in Table 2. 
A

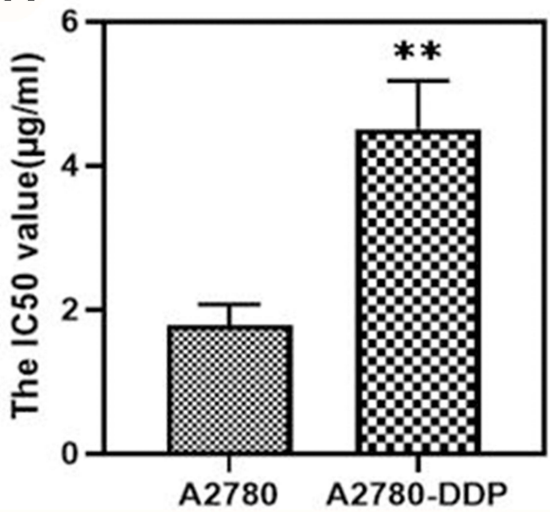

B

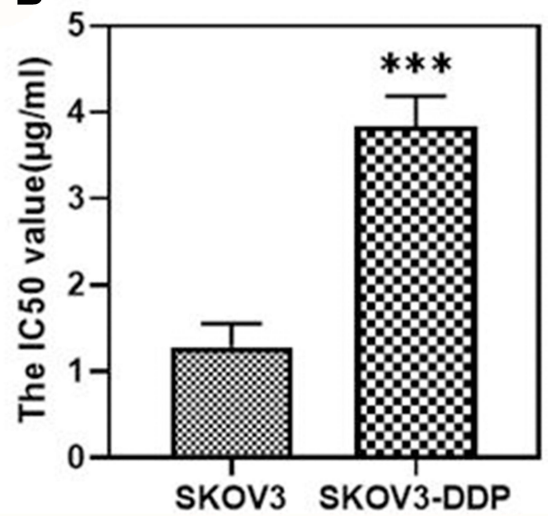

Figure $3 \mathrm{IC}_{50}$ values of sensitive and cisplatin-resistant cells of ovarian cancer. (A) IC 50 in A2780 and A2780-DDP; (B) IC 50 in SKOV3 and SKOV3-DDP. Notes: $* * P<0.01$, *** $P<0.005$.

\section{A}

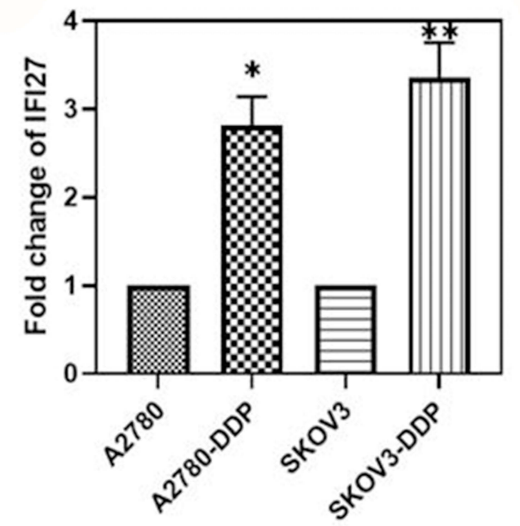

B

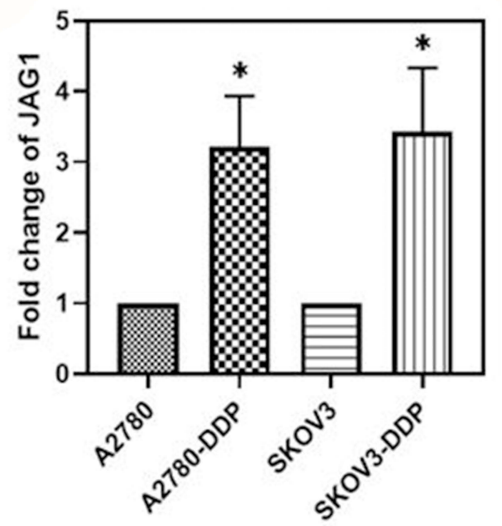

C

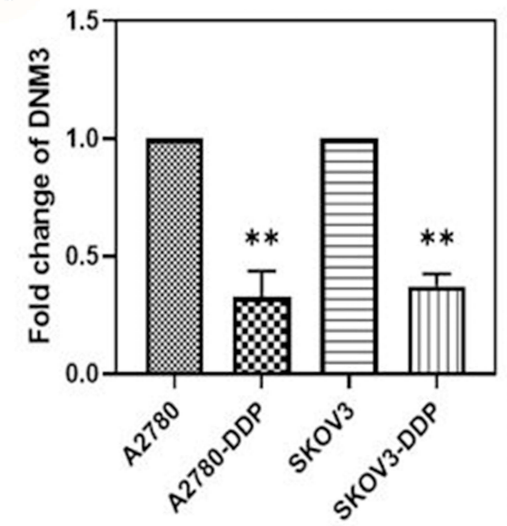

Figure 4 The mRNA expression of each gene in ovarian cancer sensitive and cisplatin-resistant cells by qRT-PCR. (A) mRNA expression of IFI27 in ovarian cancer cells; (B) mRNA expression of JAGI; (C) mRNA expression of DNM3.

Notes: $* \mathrm{P}<0.05, * * \mathrm{P}<0.01$.

The Relationship Between Gene Expression and Survival Analysis in Platinum-Resistant Clinical Patients with Ovarian Cancer

There was no distinction between $J A G 1$ and the overall survival (OS) or progression-free survival (PFS) of platinum-resistance ( $\mathrm{P}>0.05)$, but IFI27 expression was significantly different from the OS in drug-resistant patients, and DNM3 were statistically different from the OS and PFS. The survival time of patients with weak IFI27 expression was significantly improved, while the survival time was prolonged after increasing DNM3. The survival curves of each gene are shown in Figure 6.

\section{Binary Logistic of Risk Factors Affecting} Platinum-Resistant Patients

The calculation results of binary logistic regression analysis showed that the expression level of IFI27 (HR $=0.434$,
$\mathrm{P}<0.05,95 \% \mathrm{CI}=0.219-0.861)$ and DNM3 $(\mathrm{HR}=3.124$, $\mathrm{P}<0.05,95 \% \mathrm{CI}=1.311-7.445)$, tumor residue $(\mathrm{HR}=$ $0.059, \mathrm{P}<0.0001,95 \% \mathrm{CI}=0.016-0.212)$ and recurrence $(\mathrm{HR}=5.991, \mathrm{P}<0.0001,95 \% \mathrm{CI}=2.410-14.890)$ may be independent factors affecting platinum-resistant ovarian cancer patients. See Table 3 for details.

To Judge the Diagnostic Value of Genes as Sensitive Indicators of Ovarian Cancer

ROC curves analysis data were as follows. The sensitivity, specificity, AUC and P value of IFI27 expression to predict chemosensitivity were $0.371,0.449,0.596$ and 0.036 ( $\mathrm{P}<0.05)$, respectively. The values of $J A G 1$ were 0.714 , $0.459,0.601$ and $0.028(\mathrm{P}<0.05)$. DNM3 were 0.298, $0.878,0.581$ and $0.078(\mathrm{P}>0.05)$. The ROC curves are shown in Figure 7. Table 4 shows the positive and negative likelihood ratios. The above results indicated that 

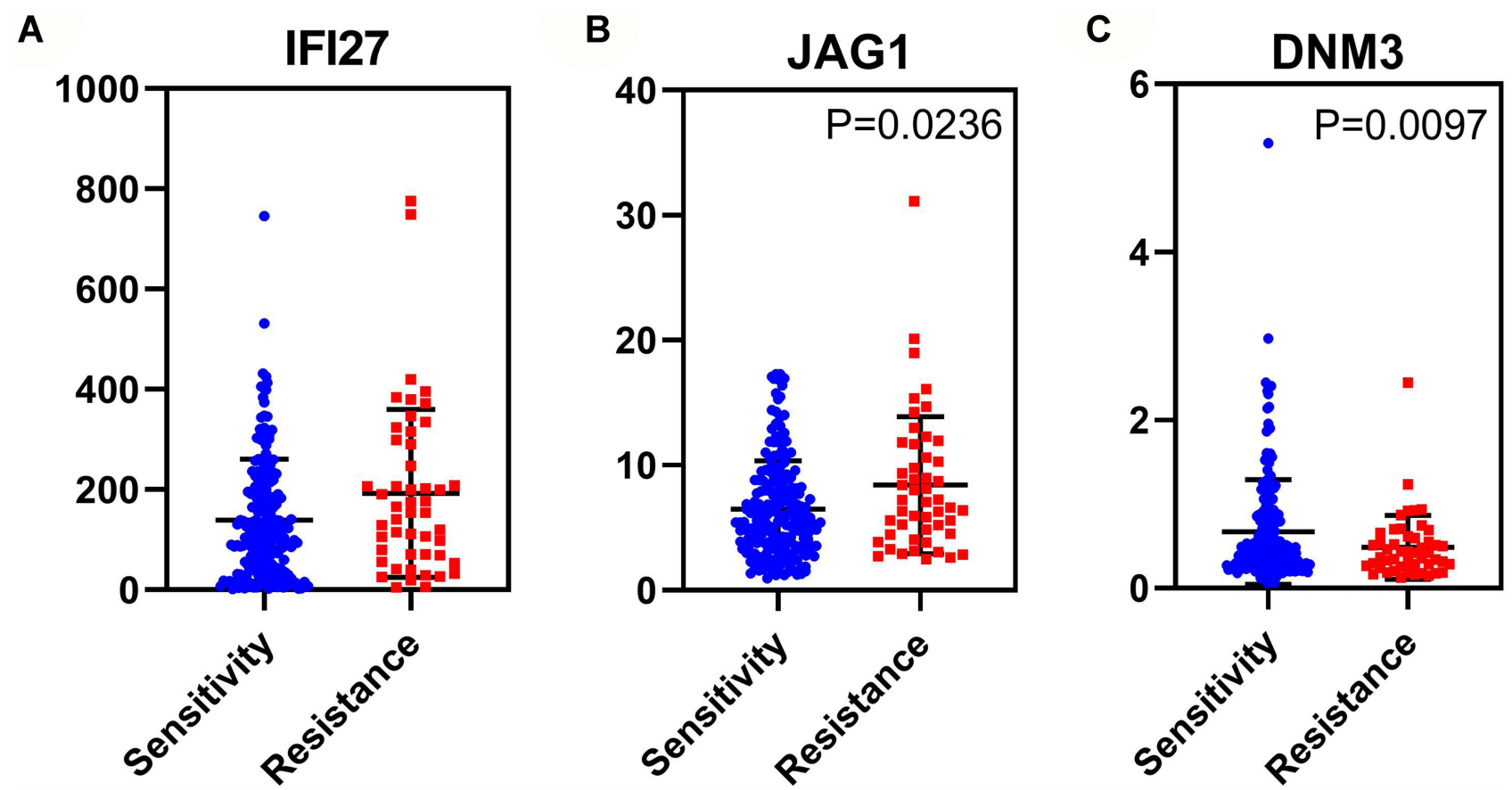

Figure 5 The expression of 3 genes in ovarian cancer chemosensitive and drug-resistant patients from TCGA. (A) mRNA expression of IFI27 in ovarian cancer cells; (B) mRNA expression of JAGI; (C) mRNA expression of DNM3.

IFI27 and DNM3 had good accuracy in deciding drug resistance, while DNM3 may need to be combined with other markers to diagnose ovarian cancer chemoresistance.

\section{Discussion}

Although the research on platinum resistance of ovarian cancer has made great progress in recent years, due to the complexity and variability of its biological characteristics, platinum resistance is still the main reason for the failure of anti-tumor treatment in most ovarian cancer patients. This study screened and proved IFI27, JAGI and DNM3 may be differential genes related to platinum resistance in ovarian cancer.

Interferon $\alpha$-inducible protein 27 (IFI27, also known as ISG12 or $p 27$ ) is located on human chromosome $14 \mathrm{q} 32$ and is encoded by one small gene that is highly induced by interferon $\alpha$ with basic expression in almost all cell types. It is reported to be related to IFN-induced apoptosis, cell proliferation, and immune responses. The complementary DNA of IFI27 was originally cloned as an estrogeninducible gene in the human epithelial cell line MCF-7 and designated as $p 27 .{ }^{4,5}$ In situ hybridization with some tumors overexpressing IFI27 shows that RNA is located in cancer cells and sometimes also in fibroblastic cells of tumor stroma. ${ }^{6}$ IFI27 is up-regulated in breast cancer, ${ }^{7,8}$ serous ovarian cancer, ${ }^{9,10}$ hepatocellular carcinoma ${ }^{11,12}$ and other malignant tumors. ${ }^{6,13,14}$ But its role in ovarian cancer remains to be elucidated. Researchers have observed through a series of basic experiments that the overexpression of IFI27 induced epithelial-mesenchymal transition and promoted the migration, invasion, tumorigenicity, stemness and drug resistance of epithelial ovarian cancer cells. ${ }^{10}$ In addition, some scientists have collected the gene expression profiles of ovarian cancer stem cells from 5 public cohorts, and obtained IFI27 (up-regulated), one of the core genes that co-expressed using bioinformatics methods, ${ }^{15}$ and pointed out that IFI27 belongs to one of the most widely up-regulated genes in cancer, and is involved in apoptosis, metabolism, cell cycle, tumor growth and suppression. ${ }^{16}$ Kim et al have used RT-PCR based on the annealing controlled primer system to identify differentially expressed genes in patients with stage III serous ovarian cancer, and found IFI27 was up-regulated in most stage III patients. ${ }^{17}$ In summary, higher IFI27 expression is linked to the inferior OS in ovarian cancer patients.

Human $J A G 1$ is encoded by the $20 \mathrm{p} 12.2$ chromosome and consists of 26 exons. JAG1 is an important Notch ligand, which can trigger Notch signal transduction through intercellular interactions. ${ }^{18}$ JAG1 stimulates the abnormal activation of Notch signal to participate in tumor growth by maintaining the cancer stem cell 
Table 2 IFI27, JAGI and DNM3 Expression and Clinicopathological Parameters of Ovarian Cancer in TCGA

\begin{tabular}{|c|c|c|c|c|c|c|c|c|c|c|c|c|c|}
\hline \multirow[t]{2}{*}{ Parameters } & \multirow[t]{2}{*}{ n (\%) } & \multicolumn{2}{|c|}{$\begin{array}{l}\text { IFI27 } \\
\text { Expression }\end{array}$} & \multirow[t]{2}{*}{$\chi^{2}$} & \multirow[t]{2}{*}{ P value } & \multicolumn{2}{|c|}{$\begin{array}{l}\text { JAG I } \\
\text { Expression }\end{array}$} & \multirow[t]{2}{*}{$\chi^{2}$} & \multirow[t]{2}{*}{$P$ value } & \multicolumn{2}{|c|}{$\begin{array}{l}\text { DNM3 } \\
\text { Expression }\end{array}$} & \multirow[t]{2}{*}{$\chi^{2}$} & \multirow[t]{2}{*}{$P$ value } \\
\hline & & Low & High & & & Low & High & & & Low & High & & \\
\hline $\begin{array}{l}\text { Age (years) } \\
\leq 55 \\
>55\end{array}$ & $\begin{array}{l}105(41.33) \\
149(58.66)\end{array}$ & $\begin{array}{l}60 \\
93\end{array}$ & $\begin{array}{l}45 \\
56\end{array}$ & 0.715 & 0.398 & $\begin{array}{l}64 \\
88\end{array}$ & $\begin{array}{l}41 \\
61\end{array}$ & 0.092 & 0.762 & $\begin{array}{l}73 \\
99\end{array}$ & $\begin{array}{l}32 \\
50\end{array}$ & 0.267 & 0.605 \\
\hline $\begin{array}{l}\text { Degree of } \\
\text { resistance } \\
\text { Sensitivity } \\
\text { Resistance }\end{array}$ & $\begin{array}{l}205(80.70) \\
49(19.29)\end{array}$ & $\begin{array}{l}130 \\
20\end{array}$ & $\begin{array}{l}75 \\
29\end{array}$ & 8.352 & 0.004 & $\begin{array}{l}87 \\
30\end{array}$ & $\begin{array}{l}118 \\
19\end{array}$ & 5.617 & 0.018 & $\begin{array}{l}137 \\
25\end{array}$ & $\begin{array}{l}68 \\
24\end{array}$ & 4.278 & 0.039 \\
\hline $\begin{array}{l}\text { Recurrence } \\
\text { No } \\
\text { Yes }\end{array}$ & $\begin{array}{l}76(29.92) \\
178(70.08)\end{array}$ & $\begin{array}{l}49 \\
104\end{array}$ & $\begin{array}{l}27 \\
74\end{array}$ & 0.813 & 0.361 & $\begin{array}{l}34 \\
110\end{array}$ & $\begin{array}{l}42 \\
68\end{array}$ & 6.314 & 0.012 & $\begin{array}{l}45 \\
132\end{array}$ & $\begin{array}{l}31 \\
46\end{array}$ & 5.632 & 0.018 \\
\hline $\begin{array}{l}\text { Histological grade } \\
\text { GI/G2 } \\
\text { G3/G4 } \\
\text { Missing }\end{array}$ & $\begin{array}{l}33(12.99) \\
214(84.25) \\
7(2.76)\end{array}$ & $\begin{array}{l}16 \\
132\end{array}$ & $\begin{array}{l}17 \\
82\end{array}$ & 2.074 & 0.150 & $\begin{array}{l}19 \\
129\end{array}$ & $\begin{array}{l}14 \\
85\end{array}$ & 0.087 & 0.768 & $\begin{array}{l}23 \\
142\end{array}$ & $\begin{array}{l}10 \\
72\end{array}$ & 0.144 & 0.704 \\
\hline $\begin{array}{l}\text { FIGO stage } \\
\text { I/II } \\
\text { III/IV } \\
\text { Missing }\end{array}$ & $\begin{array}{l}17(6.69) \\
235(92.52) \\
2(0.79)\end{array}$ & $\begin{array}{l}12 \\
141\end{array}$ & $\begin{array}{l}5 \\
94\end{array}$ & 0.745 & 0.388 & $\begin{array}{l}11 \\
139\end{array}$ & $\begin{array}{l}6 \\
96\end{array}$ & 0.203 & 0.652 & $\begin{array}{l}7 \\
173\end{array}$ & $\begin{array}{l}10 \\
62\end{array}$ & 8.175 & 0.004 \\
\hline $\begin{array}{l}\text { Tumor residue } \\
\text { No } \\
\text { Yes } \\
\text { Missing }\end{array}$ & $\begin{array}{l}55(21.65) \\
186(73.23) \\
13(5.19)\end{array}$ & $\begin{array}{l}18 \\
109\end{array}$ & $\begin{array}{l}37 \\
77\end{array}$ & 11.401 & 0.001 & $\begin{array}{l}32 \\
112\end{array}$ & $\begin{array}{l}23 \\
74\end{array}$ & 0.073 & 0.787 & $\begin{array}{l}35 \\
125\end{array}$ & $\begin{array}{l}20 \\
61\end{array}$ & 0.242 & 0.623 \\
\hline $\begin{array}{l}\text { Survival status } \\
\text { Alive } \\
\text { Dead }\end{array}$ & $\begin{array}{l}99(38.98) \\
155(61.02)\end{array}$ & $\begin{array}{l}66 \\
82\end{array}$ & $\begin{array}{l}33 \\
73\end{array}$ & 4.706 & 0.030 & $\begin{array}{l}55 \\
97\end{array}$ & $\begin{array}{l}44 \\
58\end{array}$ & 1.241 & 0.265 & $\begin{array}{l}64 \\
108\end{array}$ & $\begin{array}{l}35 \\
47\end{array}$ & 0.699 & 0.403 \\
\hline
\end{tabular}

populations, promoting cell survival, and inhibiting cell apoptosis. Many references have reported that $J A G 1$ overexpression occurs in many different types of cancer and is associated with poor clinical prognosis. JAG1/Notch signaling cascade will activate plenty of oncogenic factors that regulate important cellular functions, such as metastasis, proliferation, angiogenesis, and drug-resistance. ${ }^{19}$ $J A G 1$ can crosstalk with the JAK/STAT3 pathway and jointly promote the abnormal occurrence of epithelialmesenchymal transition (EMT), thereby further reinforcing the invasion and migration ability of ovarian cancer in vivo and in vitro. ${ }^{20}$ In addition, knocking down $J A G 1$ can inhibit Notch signal activation, and significantly suppress the proliferation, migration, invasion, stemness, and resistance of ovarian cancer cells to chemotherapy drugs such as doxorubicin and cisplatin. ${ }^{21}$ Studies have also concluded that siRNA can silence $J A G 1$ and reverse taxane chemoresistance, and $J A G 1$ plays a dual role in cancer progression through its angiogenic function in tumor endothelial cells, as well as proliferation and chemoresistance. ${ }^{22}$ According to the literature, as an oncogene, the reduction of $J A G 1$ expression is of positive significance for patients with chemotherapy-resistant ovarian cancer.

DNM3 (Dynamin 3) encodes a member of the guanosine triphosphate (GTP) binding protein family that associates with microtubules and participates in vesicular transport. ${ }^{23}$ The protein it encodes plays a role in the development of megakaryocytes. ${ }^{24}$ DNM3 is a newly discovered tumor suppressor gene. Genome Wide Association Study (GWAS) has found that compared with normal tissues, the promoter methylation level in 
A

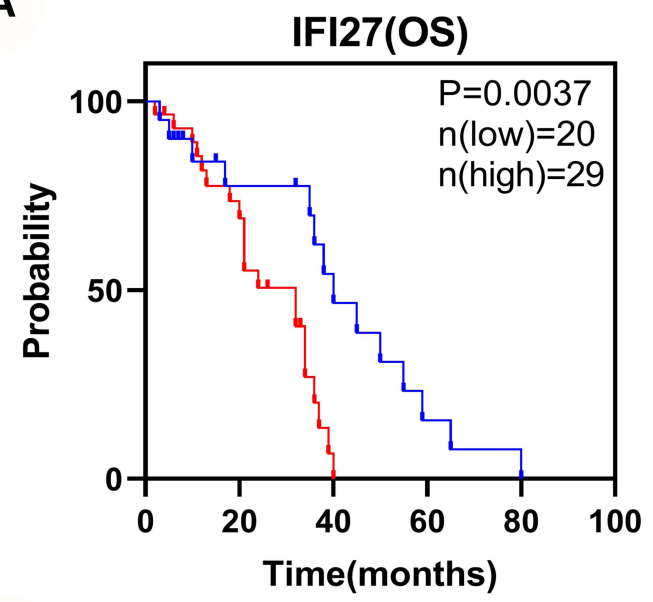

C

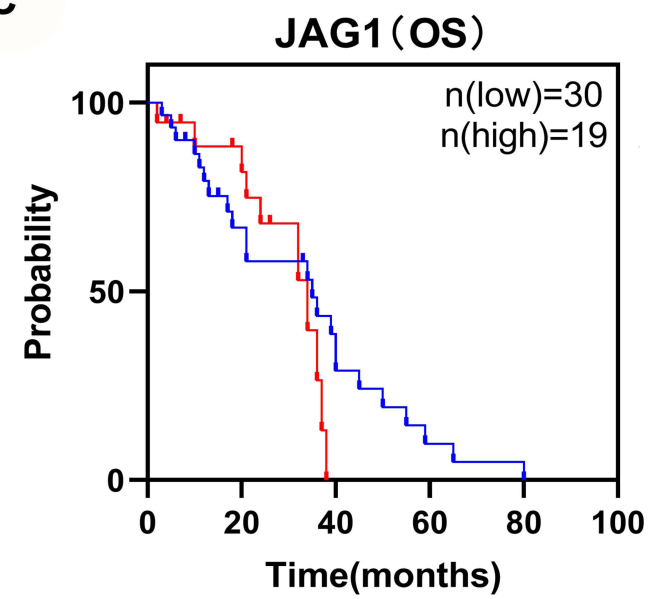

E

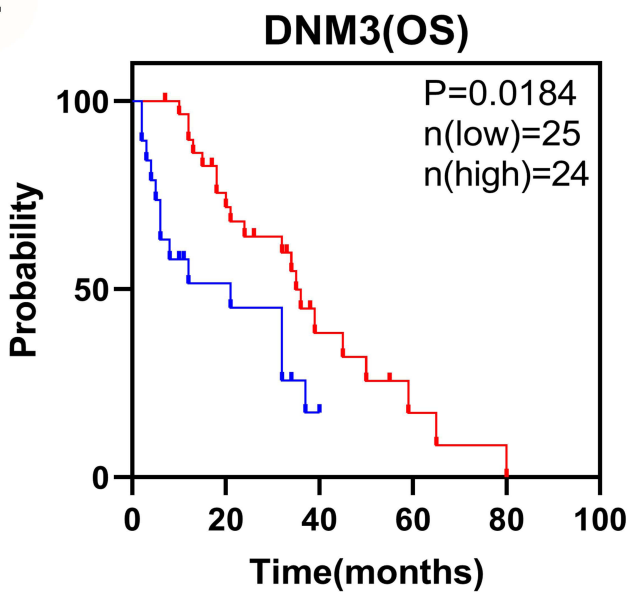

B

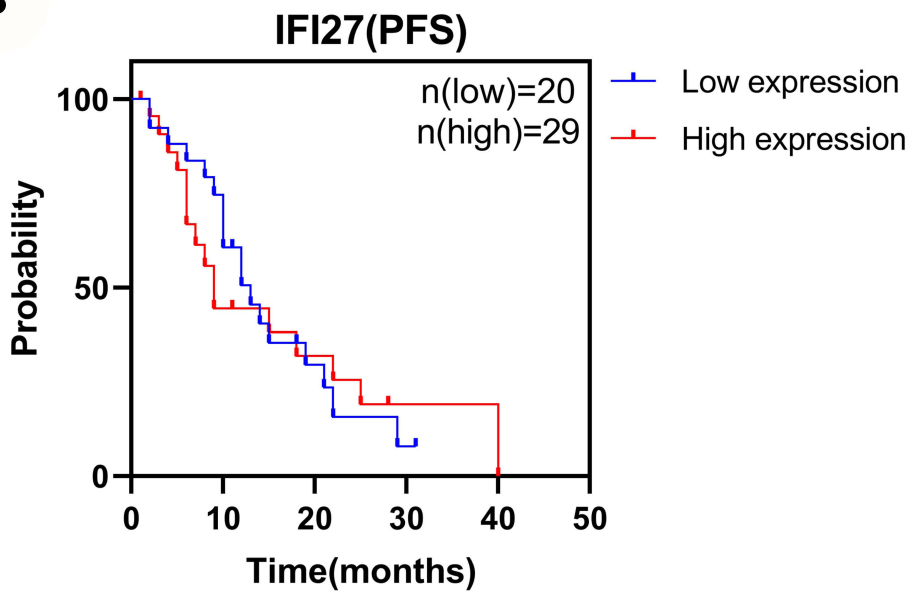

D

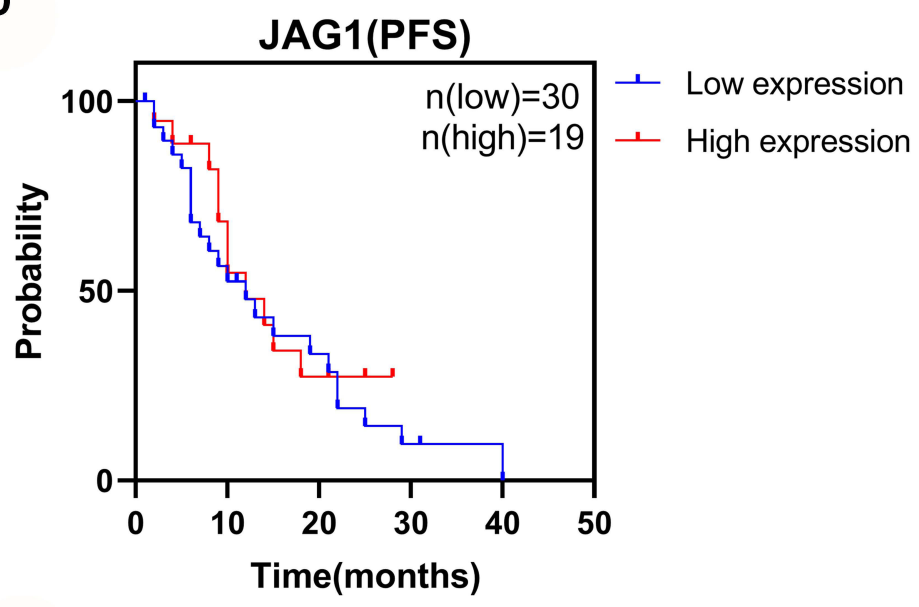

$\mathbf{F}$

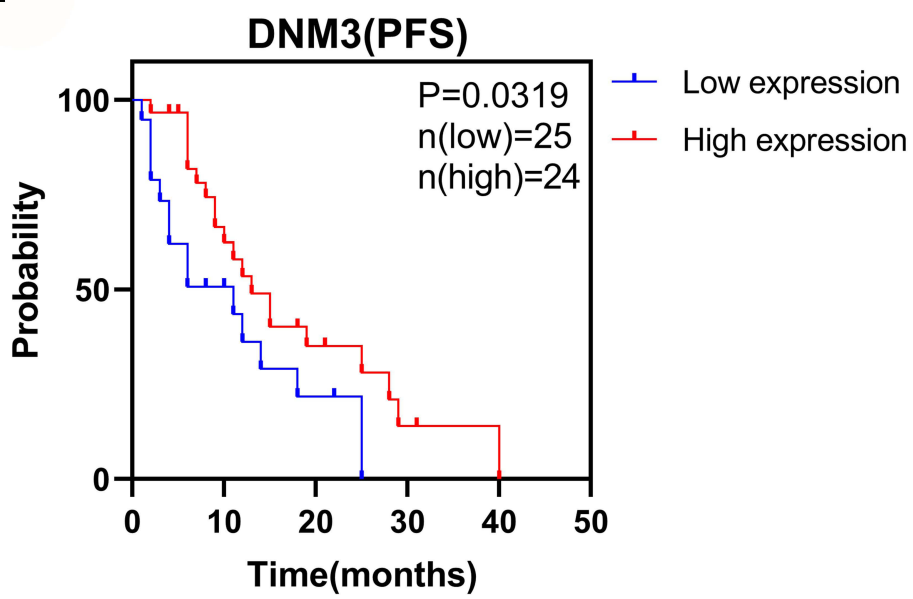

Figure 6 The relationship between the gene expression and the OS or PFS in platinum-resistant patients with ovarian cancer. (A) The relationship between IFI27 expression and the OS of ovarian cancer platinum-resistant patients; (B) IFI27 and the PFS in platinum-resistance; (C) JAGI and the OS; (D) JAGI and the PFS; (E) DNM3 and the OS; (F) DNM3 and the PFS.

cancer tissues is higher. ${ }^{25} \mathrm{Gu}$ et al have revealed that the overexpression of DNM3 may induce hepatocellular carcinoma cell apoptosis and inhibit tumor growth by activating the production of inducible nitric oxide synthase (iNOS) and the subsequent NO-ROS signaling pathway. ${ }^{26}$ Zhang et al have found that the up-regulation of DNM3 reduces 
Table 3 Binary Logistics Regression to Evaluate the Factors Influencing Platinum-Resistant Ovarian Cancer Patients

\begin{tabular}{|l|l|l|l|}
\hline Parameters & P value & HR & $\mathbf{9 5 \%}$ CI \\
\hline IFI27 expression level & 0.017 & 0.434 & $0.219-0.861$ \\
JAGI expression level & 0.115 & 0.582 & $0.297-1.140$ \\
DNM3 expression level & 0.010 & 3.124 & $1.311-7.445$ \\
Age & 0.923 & 0.966 & $0.483-1.932$ \\
Survival status & 0.650 & 1.220 & $0.517-2.877$ \\
Histological grade & 0.887 & 1.071 & $0.418-2.746$ \\
FIGO stage & 0.491 & 0.474 & $0.057-3.971$ \\
Tumor residue & 0.0001 & 0.059 & $0.016-0.212$ \\
Recurrence & 0.0001 & 5.991 & $2.410-14.890$ \\
\hline
\end{tabular}

the proliferation and colony formation of hepatocellular carcinoma, and induces the arrest of cancer cells in G0/G1 phase. ${ }^{23}$ Clinical trials have confirmed that patients with reduced expression of DNM3 in tumor tissues have a lower survival rate and a worse prognosis. ${ }^{27}$ However, the research on the relationship between DNM3 and malignancy is still insufficient, and the exact molecular mechanism is unclear.

Three genes we screened from the gene microarray datasets were verified the expression levels of ovarian cancer cells and clinical samples based on public databases. IFI27 and JAG1 in the platinum-resistant group were higher than those in sensitivity, while DNM3 was the opposite. This conclusion was consistent with the qRT-PCR verification results. In the TCGA database, hierarchical analysis showed IFI27, JAG1, and DNM3 expression levels were all related to the chemoresistance. The survival curves of platinum-resistant patients suggested that the survival time with reduced IFI27 was significantly prolonged, while the OS and
PFS in DNM3 low-expressed group were decreased accordingly. Binary logistic regression calculated that the expression of IFI27 and DNM3, tumor residue and recurrence status seriously affected the prognosis of platinum-resistant patients. The $\mathrm{P}$ predicting the chemotherapy outcome revealed IFI27 and JAG1 had certain diagnostic values for the platinum-sensitivity in ovarian cancer. All in all, three genes have their own merits as molecular targets for the diagnosis of platinum resistance in ovarian cancer, but the results of this study are consistent with the conclusions of most of the above-mentioned references.

There are several shortcomings in this study. First of all, both bioinformatics and clinical case data demonstrated that IFI27, JAG1, DNM3 may be key candidate genes for platinum resistance in ovarian cancer, supplemented by a large number of references, but these results still need to be verified through functional experiments. Secondly, for a single biomarker, although the analysis based on bioinformatics has certain predictive values, it is still necessary to further improve the predictive effects by combining with other biomarkers.

Predicting chemoresistance for ovarian cancer is difficult. This study provides partial theoretical and clinical basis for platinum resistance in ovarian cancer. In future clinical practice, drugs that inhibit IFI27 and JAGI (or inhibit $J A G 1 /$ Notch signaling pathway) or activate $D N M 3$ expression may enhance the sensitivity of platinum drugs. They work together to promote the effectiveness of platinum therapy on ovarian cancer cells in patients. Even if the development of drugs is subject to numerous obstacles, we still look forward to follow-up related research on these 3 genes.
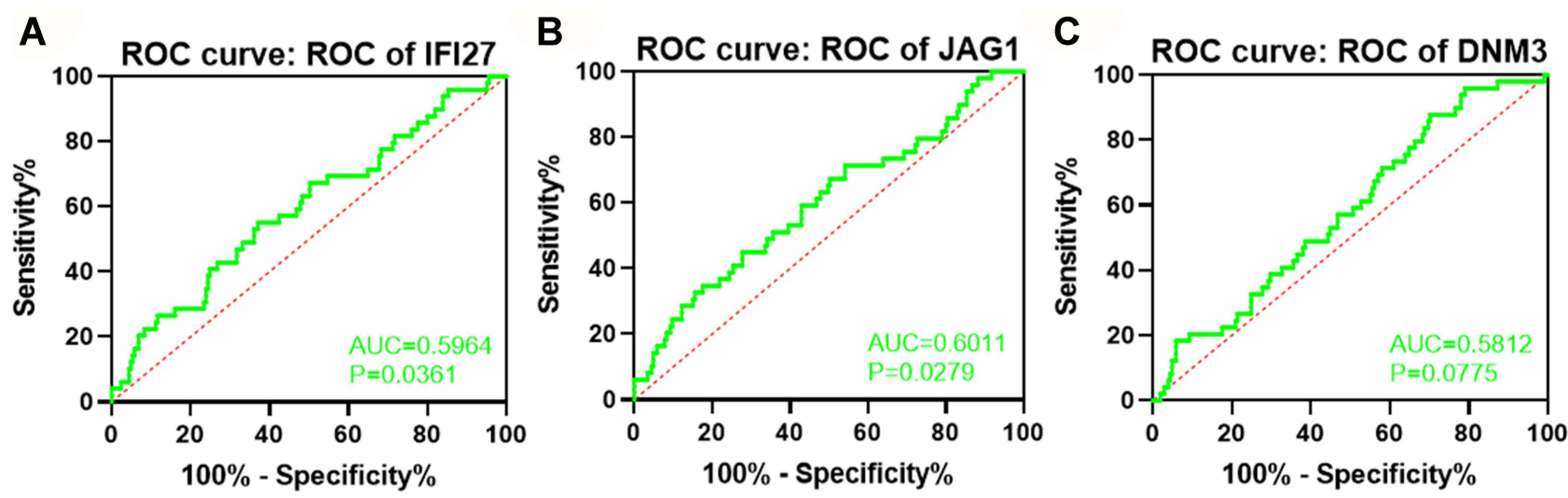

Figure 7 ROC curves to determine the genes as indicators of ovarian cancer chemosensitivity (A-C). 
Table 4 The Ability of Genes to Predict Chemotherapy Outcomes in Ovarian Cancer

\begin{tabular}{|l|l|l|l|l|l|l|l|}
\hline Gene & AUC (95\% CI) & P & Youden & Sensitivity & Specificity & $\begin{array}{l}\text { Positive Likelihood } \\
\text { Ratio }\end{array}$ & $\begin{array}{l}\text { Negative Likelihood } \\
\text { Ratio }\end{array}$ \\
\hline IFI27 & $0.5964(0.506-0.686)$ & 0.0361 & 0.180 & 0.371 & 0.449 & 1.402 & 0.673 \\
JAGI & 0.601 I (0.510-0.692) & 0.0279 & 0.173 & 0.714 & 0.459 & 1.319 & 0.623 \\
DNM3 & $0.5812(0.497-0.666)$ & 0.0775 & 0.175 & 0.298 & 0.878 & 2.430 & 0.800 \\
\hline
\end{tabular}

Abbreviation: AUC, area under the curve.

\section{Ethics Approval and Consent to Participate}

Approval of ethical review board Number: LW2021088. The research on human genetic resources materials in the "Prediction of key candidate genes for platinum resistance in ovarian cancer" by Kaidi Guo was received by the Ethics Committee of Guangxi Medical University Cancer Hospital, and it was considered that the study met the requirements of medical ethics.

\section{Acknowledgments}

We acknowledge TCGA and GEO database for providing their platforms and contributors for uploading their meaningful datasets.

Thanks to my supervisor, Professor $\mathrm{Li} \mathrm{Li}$, for providing guidance and modification suggestions of this research, which has benefited me a lot.

\section{Author Contributions}

All authors made a significant contribution to the work reported, whether that is in the conception, study design, execution, acquisition of data, analysis and interpretation, or in all these areas; took part in drafting, revising or critically reviewing the article; gave final approval of the version to be published; have agreed on the journal to which the article has been submitted; and agree to be accountable for all aspects of the work.

\section{Funding}

This research did not receive any specific grant from funding agencies in the public, commercial, or not-forprofit sectors.

\section{Disclosure}

The authors declare that they have no competing interests.

\section{References}

1. Al Habyan S, Kalos C, Szymborski J, et al. Multicellular detachment generates metastatic spheroids during intra-abdominal dissemination in epithelial ovarian cancer. Oncogene. 2018;37(37):5127-5135. doi:10.1038/s41388-018-0317-x

2. Fitzmaurice C, Allen C, Barber RM, et al. Global, regional, and national cancer incidence, mortality, years of life lost, years lived with disability, and disability-adjusted life-years for 32 cancer groups, 1990 to 2015: a systematic analysis for the Global Burden of Disease Study. JAMA Oncol. 2017;3(4):524-548. doi:10.1001/ jamaoncol.2016.5688

3. Mikuła-Pietrasik J, Witucka A, Pakuła M, et al. Comprehensive review on how platinum- and taxane-based chemotherapy of ovarian cancer affects biology of normal cells. Cell Mol Life Sci. 2019;76 (4):681-697. doi:10.1007/s00018-018-2954-1

4. Cervantes-Badillo MG, Paredes-Villa A, Gómez-Romero V, et al. IFI27/ISG12 downregulates estrogen receptor alpha transactivation by facilitating its interaction with CRM1/XPO1 in breast cancer cells. Front Endocrinol. 2020;11:568375. doi:10.3389/fendo.2020.568375

5. Hsieh WL, Huang YH, Wang TM, et al. IFI27, a novel epidermal growth factor-stabilized protein, is functionally involved in proliferation and cell cycling of human epidermal keratinocytes. Cell Prolif. 2015;48(2):187-197. doi:10.1111/cpr.12168

6. Chiang K-C, Huang S-T, Wu R-C, et al. Interferon $\alpha$-inducible protein 27 is an oncogene and highly expressed in cholangiocarcinoma patients with poor survival. Cancer Manag Res. 2019;11:1893-1905. doi:10.2147/CMAR.S196485

7. Rasmussen UB, Wolf C, Mattei MG, et al. Identification of a new interferon-alpha-inducible gene (p27) on human chromosome 14q32 and its expression in breast carcinoma. Cancer Res. 1993;53 (17):4096-4101.

8. Pillay K, McCleod H, Chetty R, et al. A study to investigate the role of p27 and cyclin E immunoexpression as a prognostic factor in early breast carcinoma. World J Surg Oncol. 2011;9(1):31. doi:10.1186/ 1477-7819-9-31

9. Kim SY, Kong WS, Cho JY. Identification of differentially expressed genes in Flammulina velutipes with anti-tyrosinase activity. Curr Microbiol. 2011;62(2):452-457. doi:10.1007/s00284-010-9728-9

10. Li S, Xie Y, Zhang W, et al. Interferon alpha-inducible protein 27 promotes epithelial-mesenchymal transition and induces ovarian tumorigenicity and stemness. J Surg Res. 2015;193(1):255-264. doi:10.1016/j.jss.2014.06.055

11. Budhu A, Chen Y, Kim JW, et al. Induction of a unique gene expression profile in primary human hepatocytes by hepatitis C virus core, NS3 and NS5A proteins. Carcinogenesis. 2007;28 (7):1552-1560. doi:10.1093/carcin/bgm075

12. Ullah H, Sajid M, Yan K, et al. Antiviral activity of interferon alpha-inducible protein 27 against hepatitis B virus gene expression and replication. Front Microbiol. 2021;12:656353. doi:10.3389/ fmicb.2021.656353 
13. Shang D, Han T, Xu X, Liu Y. Decitabine induces G2/M cell cycle arrest by suppressing p38/NF-kappaB signaling in human renal clear cell carcinoma. Int J Clin Exp Pathol. 2015;8(9):11140-11148.

14. Lee HR, No HK, Ryu CJ, et al. Brahma-related gene 1-associated expression of 9-27 and IFI-27 is involved in acquired cisplatin resistance of gastric cancer cells. Mol Med Rep. 2013;8(3):747-750. doi:10.3892/mmr.2013.1576

15. Zhang X, Su Y, Wu X, et al. Integrative analysis of the common genetic characteristics in ovarian cancer stem cells sorted by multiple approaches. J Ovarian Res. 2020;13(1):116. doi:10.1186/s13048020-00715-7

16. Nasr T, Bondock S, Youns M, et al. Synthesis, antitumor evaluation and microarray study of some new pyrazolo[3,4- d] $[1,2,3]$ triazine derivatives. Eur J Med Chem. 2017;141:603-614. doi:10.1016/j. ejmech.2017.10.016

17. Kim Y-S, Hwan Do J, Bae S, et al. Identification of differentially expressed genes using an annealing control primer system in stage III serous ovarian carcinoma. BMC Cancer. 2010;10(1):576. doi:10.1186/1471-2407-10-576

18. Xiu MX, Liu YM, Kuang BH. The oncogenic role of Jagged1/Notch signaling in cancer. Biomed Pharmacother. 2020;129:110416. doi:10.1016/j.biopha.2020.110416

19. Li D, Masiero M, Banham AH, Harris AL. The notch ligand JAGGED1 as a target for anti-tumor therapy. Front Oncol. 2014;4:254. doi:10.3389/fonc.2014.00254

20. Yang J, Xing H, Lu D, et al. Role of Jagged1/STAT 3 signalling in platinum-resistant ovarian cancer. J Cell Mol Med. 2019;23 (6):4005-4018. doi:10.1111/jcmm. 14286
21. Liu Z, Zhu Y, Li F, et al. GATA1-regulated JAG1 promotes ovarian cancer progression by activating notch signal pathway. Protoplasma. 2020;257(3):901-910. doi:10.1007/s00709-019-01477-w

22. Steg AD, Katre AA, Goodman B, et al. Targeting the notch ligand JAGGED1 in both tumor cells and stroma in ovarian cancer. Clin Cancer Res. 2011;17(17):5674-5685. doi:10.1158/1078-0432.CCR11-0432

23. Zhang Z, Chen C, Guo W, et al. DNM3 attenuates hepatocellular carcinoma growth by activating P53. Med Sci Monit. 2016;22:197-205. doi:10.12659/MSM.896545

24. Reems JA, Wang W, Tsubata K, et al. Dynamin 3 participates in the growth and development of megakaryocytes. Exp Hematol. 2008;36 (12):1714-1727. doi:10.1016/j.exphem.2008.08.010

25. Shen J, Wang S, Zhang Y-J, et al. Genome-wide DNA methylation profiles in hepatocellular carcinoma. Hepatology. 2012;55 (6):1799-1808. doi:10.1002/hep.25569

26. Gu C, Yao J, Sun P. Dynamin 3 suppresses growth and induces apoptosis of hepatocellular carcinoma cells by activating inducible nitric oxide synthase production. Oncol Lett. 2017;13(6):4776-4784. doi:10.3892/ol.2017.6057

27. Inokawa $Y$, Nomoto $S$, Hishida $M$, et al. Dynamin 3: a new candidate tumor suppressor gene in hepatocellular carcinoma detected by triple combination array analysis. Onco Targets Ther. 2013;6:1417-1424. doi:10.2147/OTT.S51913
International Journal of General Medicine

\section{Publish your work in this journal}

The International Journal of General Medicine is an international, peer-reviewed open-access journal that focuses on general and internal medicine, pathogenesis, epidemiology, diagnosis, monitoring and treatment protocols. The journal is characterized by the rapid reporting of reviews, original research and clinical studies

\section{Dovepress}

across all disease areas. The manuscript management system is completely online and includes a very quick and fair peer-review system, which is all easy to use. Visit http://www.dovepress.com/ testimonials.php to read real quotes from published authors. 